\title{
Mass removal modes in the laser ablation of silicon by a Q-switched diode-pumped solid-state laser (DPSSL)
}

\author{
Daniel J Lim ${ }^{1}$, Hyungson $\mathrm{Ki}^{2}$ and Jyoti Mazumder ${ }^{3}$ \\ ${ }^{1}$ Singapore Institute of Manufacturing Technology, Singapore \\ ${ }^{2}$ Mechanical Engineering Department, Michigan State University, East Lansing, \\ MI 48824-1226, USA \\ ${ }^{3}$ Centre for Laser Aided Intelligent Manufacturing, University of Michigan, Ann Arbor, \\ MI 48109-2125, USA
}

Received 26 March 2006, in final form 17 April 2006

Published 2 June 2006

Online at stacks.iop.org/JPhysD/39/2624

\begin{abstract}
A fundamental study on the Q-switched diode-pumped solid-state laser interaction with silicon was performed both experimentally and numerically. Single pulse drilling experiments were conducted on N-type silicon wafers by varying the laser intensity from $10^{8}-10^{9} \mathrm{~W} \mathrm{~cm}^{-2}$ to investigate how the mass removal mechanism changes depending on the laser intensity. Hole width and depth were measured and surface morphology was studied using scanning electron microscopy. For the numerical model study, Ki et al's self-consistent continuous-wave laser drilling model (2001 J. Phys. D: Appl. Phys. 34 364-72) was modified to treat the solidification phenomenon between successive laser pulses. The model has the capabilities of simulating major interaction physics, such as melt flow, heat transfer, evaporation, homogeneous boiling, multiple reflections and surface evolution. This study presents some interesting results on how the mass removal mode changes as the laser intensity increases.
\end{abstract}

\section{Introduction}

Owing to the current interest in microfabrication, pulsed lasers have been re-discovered as a highly enabling tool for precision machining for a wide range of engineering materials. One of the most important area of application of pulsed lasers is the microfabrication of semiconductors due to evergrowing microelectronics industry and a variety of practical MEMS applications, such as fabrication of microchannels and biochips. It was reported that about $25 \%$ of the laser machining systems sold in the year 2000 were used for the semiconductor industry [2]. Recently, picosecond (ps) and femtosecond (fs) lasers have emerged as the next generation processing tools due to their superior ablation quality and have been quickly replacing relatively longer pulse nanosecond (ns) lasers. Although shorter pulse lasers are now highlighted as the new generation precision micromachining tool [3-5], ns lasers, such as the Q-switched Nd: YAG lasers, are still the most commonly available lasers. However, there have not been many successful reports on ns laser micromachining of silicon due to the brittleness of silicon and the highly localized heating during laser processing which lead to the high density of microcracks near the laser cut zone [6]. Contrary to common belief, in fact, even fs lasers have not demonstrated good ablation qualities in some situations. For example, it has been reported that fs lasers produce mediocre results in the microfabrication of semiconductors in contrast to other types of materials, and there has not been a clear explanation for this phenomenon yet [7-9].

The capacities of ns lasers in terms of microfabrication of silicon have not been fully realized mainly because complex transport phenomena and mass removal mechanisms have not been fully understood. It has been revealed [1,10] that fluid flow, evaporation and homogeneous boiling are three major mass removal mechanisms in the ns laser interaction with materials and are very intimately coupled with process parameters and target geometry, which makes computational modelling very challenging. As far as the authors know, there has not been an extensive study on the role of these three mass removal mechanisms in the ns laser machining of silicon. 
In this paper, a high-brightness, high-average power diode-pumped solid-state Nd : YAG laser (DPSSL, model DP11, Manufacturer: Northrop Grumman) was used for the drilling experiment. To study the effect of laser drilling due to a single pulse, a high-speed external shutter was utilized. The laser intensities were set to vary from $10^{8}$ to $10^{9} \mathrm{~W} \mathrm{~cm}^{-2}$. Using scanning electron microscopy (SEM), the hole depth and width were measured and the surface morphology was observed. For the numerical simulation, a 2D axisymmetric self-consistent drilling model by Ki et al [1] was employed to simulate the drilling of silicon by a Q-switched diodepumped solid-state laser (DPSSL) and develop a fundamental understanding of laser micromachining of silicon. The model was originally developed for the continuous-wave (CW) laser drilling of steel. By accounting for the solidification process between the laser pulses, the model can simulate pulsed lasers. Fluid flow, evaporation and homogeneous boiling were all considered as mass removal modes; the multiple reflection phenomenon was simulated using the ray tracing method. For the melt flow, recoil pressure and thermo-capillary effect were both taken into consideration. For multiple reflections, angledependent absorption coefficients were used [11]. The level set method [12] was employed to track the free surface evolution during the drilling process. This study presents a number of interesting results on the material removal modes in the pulsed laser interaction with silicon.

\section{Experimental set-up}

The laser that is used for this study is a high-brightness, high-average power diode-pumped solid state Nd: YAG laser (DPSSL, model DP-11), manufactured by Northrop Grumman (formerly known as TRW), Space \& Electronics, CA, USA. Lasing occurs at the standard infrared $(1064 \mathrm{~nm}) \mathrm{Nd}$ : YAG laser wavelength where frequency can be doubled to green $(532 \mathrm{~nm})$ and quadrupled to ultraviolet $(266 \mathrm{~nm})$ through harmonic generation. In this study, the laser is set to operate at its standard infrared $1064 \mathrm{~nm}$ wavelength. The laser utilizes an unstable resonator with a graded reflectivity output coupler, thereby generating an excellent laser beam quality $(1.3-1.7 \mathrm{X}$ diffraction limit). The beam shape is near-Gaussian. See [16] for more on the characteristics of the laser and its performance.

An N-type $\langle 100\rangle 660 \mu \mathrm{m}$ thick silicon wafer is used as the substrate. CNC codes are programmed to control the movement of the $\mathrm{X}-\mathrm{Y}$ stage and coordinate the opening and closing of the laser's shutter to perform the drilling. In this study, the laser is set to operate at a repetition rate of $200 \mathrm{~Hz}$ and pulse width of $150 \mu$ s (duty cycle of $3 \%$ ). The laser beam is further modulated by an acousto-optic modulator with each spike having a $100 \mathrm{~ns}$ full-width half-maximum (FWHM) at a period of $7 \mu \mathrm{s}$. Therefore, one laser pulse consists of roughly $21-22$ small spikes $(150 \mu \mathrm{s} / 7 \mu \mathrm{s})$. The schematic of the modulated laser pulse is shown in figure 1. A halfwaveplate is used to vary the average power from the laser in order to achieve different ablation rates without changing the laser setting, while a quarter-wave plate is used to circular polarize the final processing beam. The intensities are set to vary from $10^{8}$ to $10^{9} \mathrm{~W} \mathrm{~cm}^{-2}$, and the corresponding laser average powers are given in table 1 .

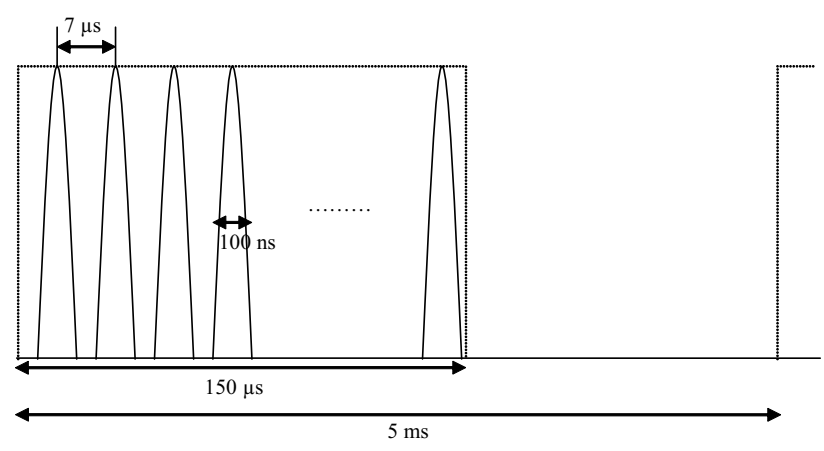

Figure 1. Schematic of a modulated laser pulse. One pulse consists of roughly $21-22$ spikes.

Table 1. Experimental parameters set up for laser drilling.

\begin{tabular}{lllllll}
\hline ID & 1 & 2 & 3 & 4 & 5 & 6 \\
\hline Power $(\mathrm{W})$ & 1.65 & 3.3 & 6.6 & 9.9 & 13.2 & 16.5 \\
$\mathrm{I}\left(\mathrm{W} \mathrm{cm}^{-2}\right)$ & $10^{8}$ & $2 \times 10^{8}$ & $4 \times 10^{8}$ & $6 \times 10^{8}$ & $8 \times 10^{8}$ & $10^{9}$ \\
\hline
\end{tabular}

Figure 2 shows the schematic of the DP-11 optical setup to study the effect of single pulse drilling. In order to study the effect of laser drilling due to single pulse, a high-speed external shutter CH-40-HS by Electro-Optical Products Corp. is used to control the number of laser pulses precisely, so that only one pulse from the laser is delivered to the substrate. When the first laser pulse signal is picked up by Thorlabs PDA50 Silicon photo diode detector, it transmits the signal to a Stanford Research System DG535 pulse generator. This in turn acts as an external trigger signal to DG535 which, in turn, generates a TTL signal with an $8 \mathrm{msec}$ pulse width to the driver board of the $\mathrm{CH}-40-\mathrm{HS}$ to control the blade of $\mathrm{CH}-40-\mathrm{HS}$ (the response time for the shutter is $2 \mathrm{msec}$ ). Generally, the blade of the $\mathrm{CH}-40-\mathrm{HS}$ is in its closed position. Upon receiving a TTL signal ('high'), the blade will switch to its open position. When the TTL signal switches to 'low', the shutter returns to its closed position. Figure 3 shows the signal sequences of the whole setup.

\section{Mathematical model}

In this section, the mathematical model is briefly presented, and the details of the model will not be given (see [1]).

\subsection{Assumptions}

(1) A Gaussian laser beam is used, and the pulse shape is given in figure 1 .

(2) Multiple reflections are simulated using the ray tracing method. The laser beam's depth of focus is not considered.

(3) Plasmas are ignored.

(4) Material properties are given in table 2. For the high temperature range they are extrapolated to the critical point using the method described in [1]. For example, surface tension values are not known for higher temperatures; they are extrapolated to the critical point using experimental data up to the normal boiling temperatures and the theoretical asymptotic behavior near the critical point [1]. 


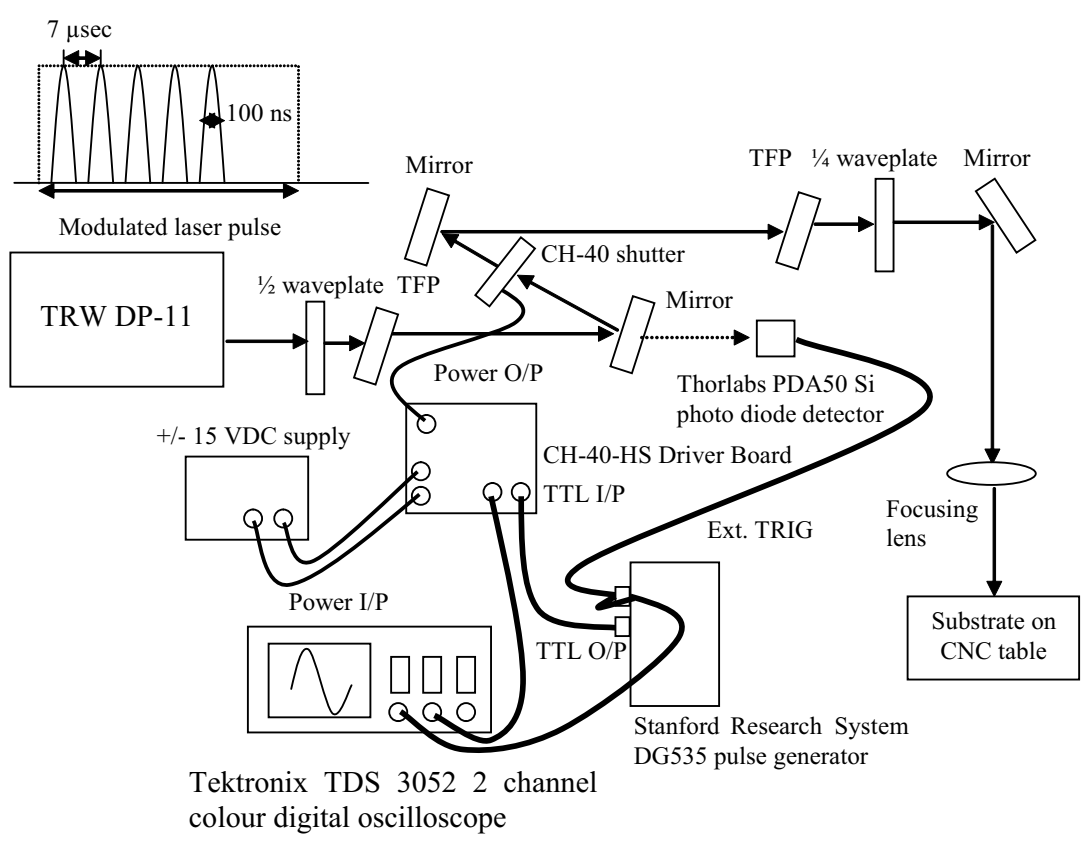

Figure 2. Schematic of DP-11 optical setup to study the effect of single pulse drilling. Each pulse consists of 11-12 spikes. An external shutter CH-40-HS together with a Thorlabs PDA50 photo diode detector and Stanford Research System DG535 pulse generator were used to control the number of laser pulses delivered to the substrate.

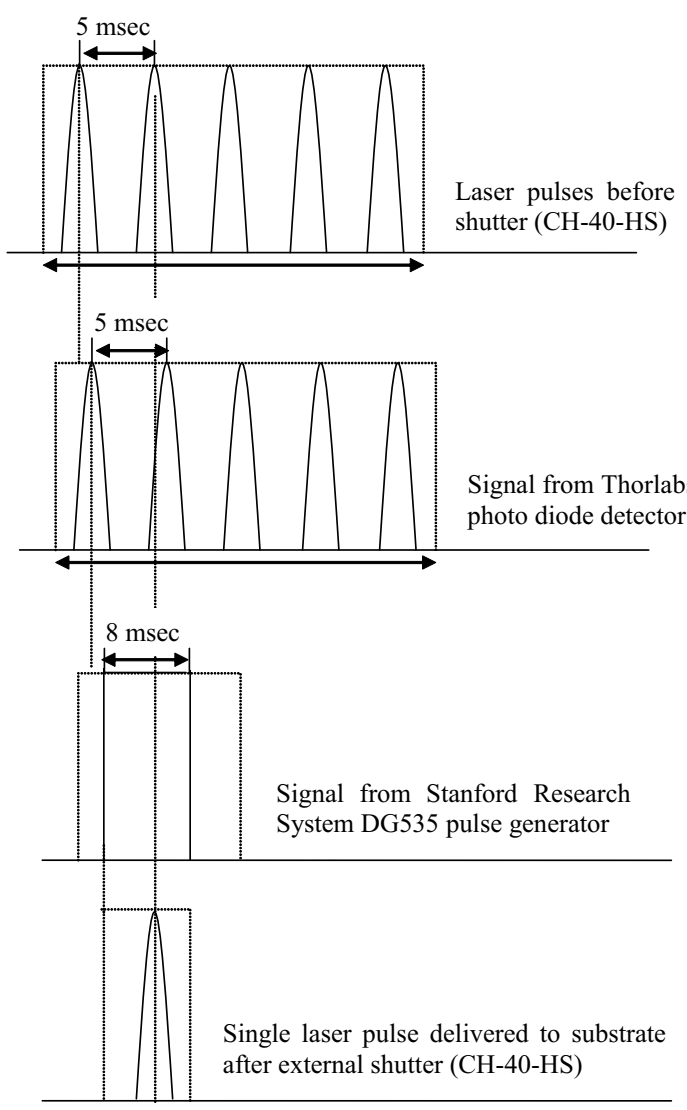

Figure 3. Signal sequences to generate a single laser pulse onto the substrate.

(5) In this study, two different values for silicon emissivity are used: 0.66 for solid and 0.27 for liquid. In other words, when silicon melts, the emissivity drops significantly from 0.66 to 0.27 . Since emissivity is close to absorptivity in many cases, these two numbers were used for silicon absorptivity. Also, angle-dependent absorption coefficients are used [11].

(6) Evaporating mass flux does not interact with the hole surfaces.

(7) The liquid layer is assumed to be very thin, so that the pressure is assumed uniform across the liquid layer from the boundary layer approximation [1].

\subsection{Mass removal mechanism}

In the laser drilling process, three mass removal modes move the liquid-vapour (L/V) interface: melt flow, evaporation and homogeneous boiling. Therefore, the surface recession speed $F$ can be decomposed into the respective components as follows:

$$
F=F_{\mathrm{f}}+F_{\mathrm{e}}+F_{\text {ho }} .
$$

Here, $F_{\mathrm{f}}, F_{\mathrm{e}}, F_{\mathrm{ho}}$ are the surface recession speeds due to fluid flow, evaporation and homogeneous boiling respectively. Melt flow effects will be discussed in the next section. Note that $F_{\mathrm{e}}$ and $F_{\mathrm{ho}}$ are assumed perpendicular to the $\mathrm{L} / \mathrm{V}$ interface.

To model evaporation, Knight's jump conditions are employed $[13,14]$. According to the model, the net mass flux $\left(\dot{m}_{\mathrm{e}}^{\prime \prime}\right)$ and energy flux $\left(\dot{q}_{\mathrm{e}}^{\prime \prime}\right)$ per unit area are calculated as

$$
\begin{gathered}
\dot{m}_{\mathrm{e}}^{\prime \prime}=\rho_{\mathrm{s}} \sqrt{\frac{R T_{\mathrm{s}}}{2 \pi}}-\rho_{\mathrm{v}} \sqrt{\frac{R T_{\mathrm{v}}}{2 \pi}} \beta F_{-}(m) \\
\dot{q}_{\mathrm{e}}^{\prime \prime}=\rho_{\mathrm{l}} L_{\mathrm{v}} F_{\mathrm{e}}
\end{gathered}
$$

Here, $\rho_{\mathrm{s}}$ and $\rho_{\mathrm{v}}$ are vapour densities (where the meanings of subscripts can be found in figure 5), $T$ is the vapour temperature, $R$ is the gas constant, $\rho_{1}$ is the liquid density and $L_{\mathrm{v}}$ is the latent heat of vaporization. The back-scattering factor $\beta F_{-}(m)$ is explained in detail in $[13,14]$. 

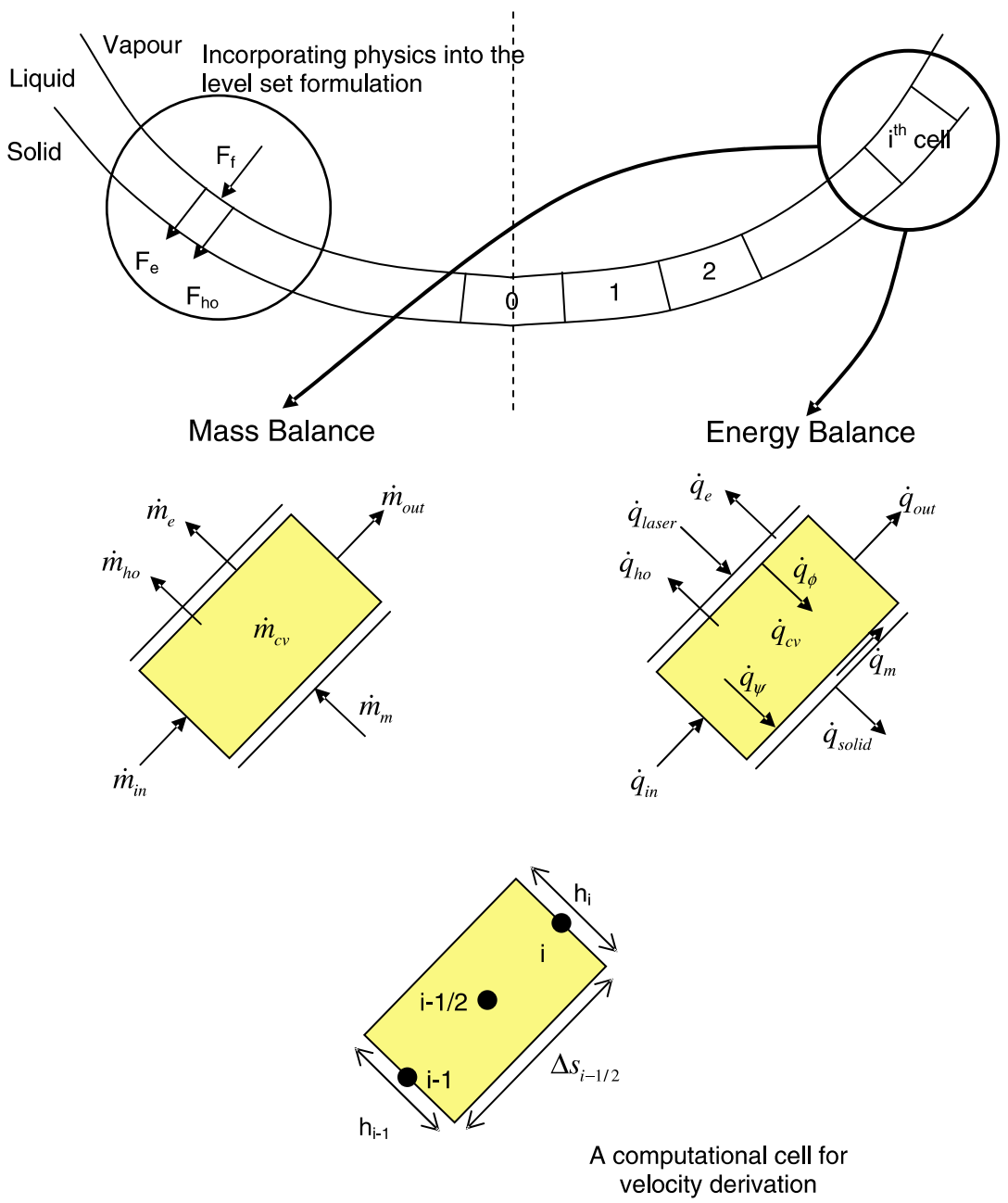

Figure 4. Mass and energy balance for a computational cell (from [1]). Subscripts e, f, ho, $\mathrm{m}$, in, out are used to indicate evaporation, fluid flow, homogeneous boiling, melting, incoming mass flux and outgoing mass flux respectively. and denote the liquid-vapour interface and the solid-liquid interface, respectively.

The surface recession speed due to evaporation can be calculated as

$$
F_{\mathrm{e}}=\dot{m}_{\mathrm{e}}^{\prime \prime} / \rho_{1} \text {. }
$$

Homogeneous boiling can occur beneath the L/V interface when the surface temperature approaches the critical temperature $\left(T_{\mathrm{c}}\right)$. The mass flux $\left(\dot{m}_{\mathrm{ho}}^{\prime \prime}\right)$ and energy flux $\left(\dot{q}_{\mathrm{ho}}^{\prime \prime}\right)$ per unit area due to homogeneous bubble generation near the critical point are [15]

$$
\begin{gathered}
\dot{m}_{\mathrm{ho}}^{\prime \prime}=J n_{\mathrm{e}} m_{\mathrm{a}} \tilde{d}, \\
\dot{q}_{\mathrm{ho}}^{\prime \prime}=J n_{\mathrm{e}}\left(\frac{3}{2} k_{\mathrm{B}} T+m_{\mathrm{a}} L_{\mathrm{v}}+\frac{4}{3} \pi \sigma r_{\mathrm{e}}^{2}\right) \tilde{d},
\end{gathered}
$$

respectively. Here, $J$ is the homogeneous nucleation rate; $n_{\mathrm{e}}$ the number of molecules in a bubble, $m_{\mathrm{a}}$ the atomic mass, $\tilde{d}$ the average thickness of the liquid layer where homogeneous boiling occurs, $k_{B}$ the Boltzmann constant $\left(1.3807 \times 10^{-23} \mathrm{~J} \mathrm{~K}^{-1}\right), T$ the liquid temperature, $\sigma$ the surface tension and the $r_{\mathrm{e}}$ bubble radius. Since the pressure across the liquid layer can be assumed constant, $\tilde{d}$ can be calculated by comparing the actual pressure profile and the saturation pressure profile determined from the temperature profile across the liquid layer [1]. Because the back-scattered flux is small as compared with the evaporating flux the actual pressure (recoil pressure) can be approximated as [1]

$$
p \cong \frac{\rho_{\mathrm{s}} v_{s}+\rho_{\mathrm{v}} v_{v}}{2 \rho_{\mathrm{s}} v_{s}} p_{\mathrm{sat}}\left(T_{\mathrm{s}}\right) .
$$

Here, $p_{\text {sat }}\left(T_{\mathrm{s}}\right)$ denotes the equilibrium pressure at $T_{\mathrm{s}}$. The surface recession speed due to homogeneous boiling can be calculated as

$$
F_{\text {ho }}=\dot{m}_{\text {ho }}^{\prime \prime} / \rho_{1} \text {. }
$$

For further details on this subject see [15].

\subsection{Melt flow}

Since the liquid layer is very thin, it can be assumed that the melt flow direction is perpendicular to the $\mathrm{L} / \mathrm{V}$ interface. With this assumption, the following simplified scheme can be obtained by integrating the Navier-Stokes equation over a computational cell:

$\left.\rho_{i-1 / 2} \Delta s_{i-1 / 2}^{n} \frac{\overline{\mathrm{d} v}}{\mathrm{~d} t}\right|_{i-1 / 2} ^{n+1}=\frac{1}{2} \rho_{i-1 / 2}\left(\overline{\left(v_{i-1}^{n}\right)^{2}}-\overline{\left(v_{i}^{n}\right)^{2}}\right)$ 


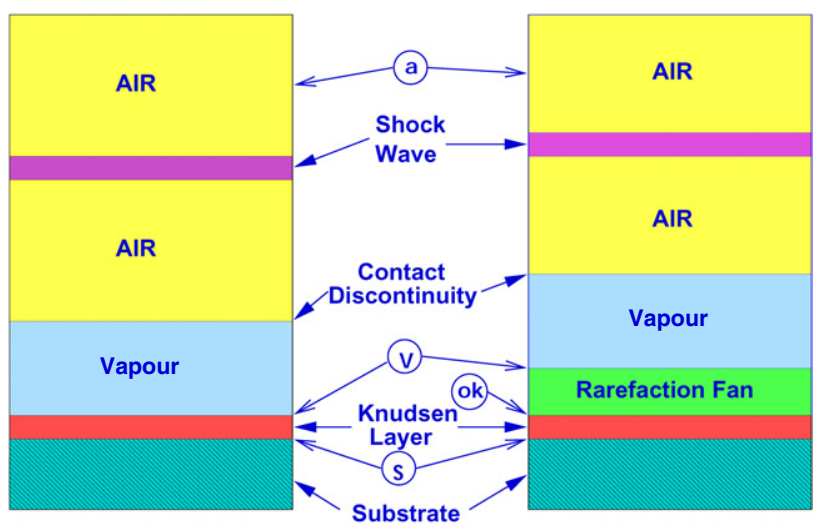

(a) Subsonic Case

(b) Supersonic Case

Figure 5. Flow structure outside the evaporating surface (from [24]). (This figure is in colour only in the electronic version)

$$
\begin{aligned}
& +\left(p_{i-1}^{n}-p_{i}^{n}\right)+\frac{\Delta s_{i-1 / 2}^{n}}{h_{i-1 / 2}^{n}}\left[\left.\mu_{i-1 / 2} \frac{\partial u}{\partial n}\right|_{\phi, i-1 / 2} ^{n}\right. \\
& \left.-\left.\mu_{i-1 / 2} \frac{\partial u}{\partial n}\right|_{\psi, i-1 / 2} ^{n}\right] .
\end{aligned}
$$

Here, the superscripts $n$ and $i$ are used for time and space respectively, while the over-bars denote variables averaged across the liquid layer. The subscripts $\phi$ and $\psi$ denote the L/V interface and the solid-liquid (S/L) interface respectively and $n$ and $s$ are the spatial variables perpendicular to and parallel to the liquid layer, respectively. The pressure $p$ is the recoil pressure and can be obtained using the method described in section 3.2. The velocity gradient at the $\mathrm{L} / \mathrm{V}$ interface is expressed as

$$
\left.\mu_{i-1 / 2} \frac{\partial u}{\partial n}\right|_{\phi, i-1 / 2} ^{n}=\left.\left.\frac{\partial \sigma}{\partial T}\right|_{i-1 / 2} ^{n} \frac{\mathrm{d} T}{\mathrm{~d} s}\right|_{\phi, i-1 / 2} ^{n},
$$

where $\sigma$ is the surface tension. The velocity gradient at the $\mathrm{S} / \mathrm{L}$ interface can be obtained by assuming a velocity profile in the liquid layer as a quadratic polynomial as follows:

$$
v(n)=\frac{1}{2 d_{i}^{n}}\left[\left.\frac{\partial u}{\partial n}\right|_{\phi, i} ^{n}-\left.\frac{\partial u}{\partial n}\right|_{\psi, i} ^{n}\right] n^{2}+\left.\frac{\partial u}{\partial n}\right|_{\psi, i} n .
$$

The surface recession speed due to melt flow $\left(F_{\mathrm{f}}\right)$ can be calculated considering the mass conservation for a cell.

\subsection{Mass and energy balance}

Figure 4 shows the schematic of mass and energy balance in the liquid layer. For a computational cell, the mass balance is expressed as

$$
\dot{m}_{\mathrm{in}}+\dot{m}_{\mathrm{m}}=\dot{m}_{\mathrm{out}}+\dot{m}_{\mathrm{e}}+\dot{m}_{\mathrm{ho}}+\dot{m}_{\mathrm{cv}}
$$

where $\dot{m}_{\text {in }}$ and $\dot{m}_{\text {out }}$ are the mass flow rates at the entrance and exit of the cell and can be obtained from the velocity profile described in the previous section. $\dot{m}_{\mathrm{m}}$ is the mass flux into the liquid layer due to melting and $\dot{m}_{\mathrm{cv}}$ is the mass accumulation rate in the cell, which is written as

$$
\dot{m}_{\mathrm{cv}}=\rho_{\mathrm{l}} A \dot{d}
$$

where $\dot{d}$ is the time rate of the liquid layer thickness and $A$ is the top surface area of the cell.

The energy balance is a little more involved due to the discontinuities at the $\mathrm{L} / \mathrm{V}$ and $\mathrm{S} / \mathrm{L}$ interfaces. The Stefan's conditions for the $\mathrm{L} / \mathrm{V}$ and $\mathrm{S} / \mathrm{L}$ interfaces are

$$
\begin{gathered}
\dot{q}_{\text {laser }}=\rho_{\mathrm{l}} L_{\mathrm{v}} A F_{\mathrm{e}}+\dot{q}_{\phi}+\dot{q}_{\text {loss }}, \\
\dot{q}_{\psi}=\rho_{\mathrm{s}} L_{\mathrm{m}} A F_{\mathrm{sl}}+\dot{q}_{\mathrm{solid}},
\end{gathered}
$$

where $\dot{q}_{\text {laser }}$ is the energy distribution after multiple reflections, $\dot{q}_{\text {loss }}$ is the energy loss to the atmosphere due to radiation and $L_{\mathrm{m}}$ is the latent heat of fusion. $\dot{q}_{\phi}, \dot{q}_{\psi}$ and $\dot{q}_{\text {solid }}$ are calculated as

$$
\dot{q}_{\phi}=-\left.k_{l} A \frac{\partial T_{l}}{\partial n}\right|_{\phi}, \quad \dot{q}_{\psi}=-\left.k_{l} A \frac{\partial T_{l}}{\partial n}\right|_{\psi},
$$

and

$$
\dot{q}_{\text {solid }}=-\left.k_{s} A \frac{\partial T_{\mathrm{s}}}{\partial n}\right|_{\psi},
$$

respectively, from the Fourier's law. The energy balance equation for a cell has a similar form as the mass balance and is expressed as

$$
\dot{q}_{\phi}+\dot{q}_{\mathrm{in}}=\dot{q}_{\psi}+\dot{q}_{\mathrm{out}}+\dot{q}_{\mathrm{cv}}+\dot{q}_{\mathrm{ho}}
$$

where $\dot{q}_{\phi}$ is the heat transferred to the liquid layer through the $\mathrm{L} / \mathrm{V}$ interface, $\dot{q}_{\text {in }}$ and $\dot{q}_{\text {out }}$ are the energy fluxes at the inlet and exit of a cell, $\dot{q}_{\psi}$ is the heat flow to the S/L interface, and $\dot{q}_{\mathrm{cv}}$ is the heat accumulation rate in the cell which accounts for the temperature change with time and can be expressed as

$$
\dot{q}_{\mathrm{cv}}=\rho_{\mathrm{l}} A d C_{p} \frac{\mathrm{d} T_{\mathrm{m}}}{\mathrm{d} t}
$$

where $C_{p}$ is the constant-pressure specific heat and $\mathrm{d} T_{\mathrm{m}} / \mathrm{d} t$ is the time rate of mean liquid temperature increase.

\subsection{Free surface evolution}

Melting and evaporation phenomena involve moving $\mathrm{L} / \mathrm{V}$ and $\mathrm{S} / \mathrm{L}$ boundaries and these boundaries have to be tracked selfconsistently in order to implement the process physics. The level set method [12] is employed to update the $\mathrm{L} / \mathrm{V}$ interface using the following equation:

$$
\frac{\partial \phi}{\partial t}+F|\nabla \phi|=0
$$

where $\phi$ is the level set function. The location of the S/L interface is calculated from the mass balance of the given cell with respect to the updated $\mathrm{L} / \mathrm{V}$ interface.

\subsection{Solidification between the pulses}

The original model was developed for the CW laser drilling process. In the particular case, the drilling process can be considered semi-stationary in the sense that two interfaces, namely the $\mathrm{S} / \mathrm{L}$ interface and the $\mathrm{L} / \mathrm{V}$ interface, exist throughout the entire drilling process. Therefore, the mass and energy balances shown in figure 4 can be applied to the welldefined liquid layer bounded by the two interfaces. However, in a pulsed laser material removal process, solidification may 


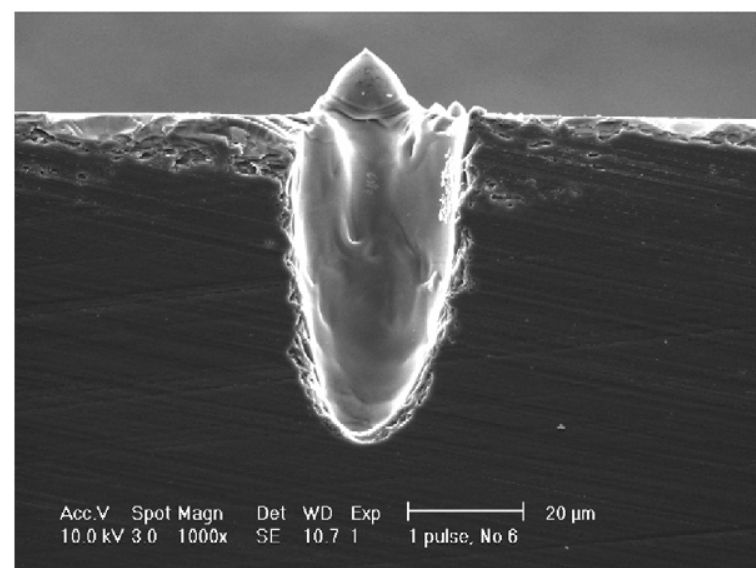

(a) $\mathrm{I}=10^{8} \mathrm{~W} / \mathrm{cm}^{2}$

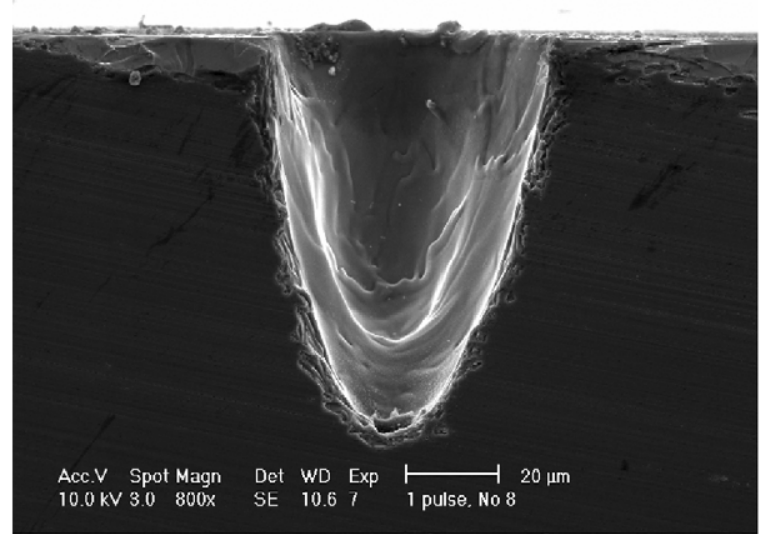

(c) $\mathrm{I}=4 \times 10^{8} \mathrm{~W} / \mathrm{cm}^{2}$

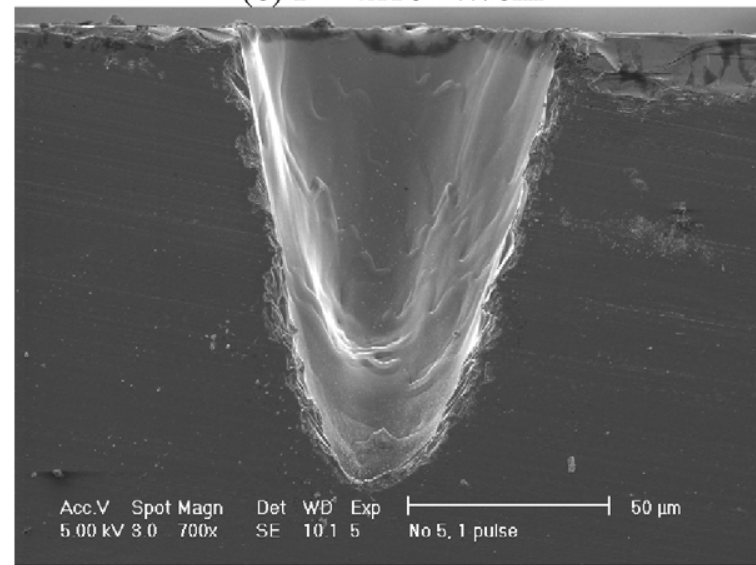

(e) $\mathrm{I}=8 \times 10^{8} \mathrm{~W} / \mathrm{cm}^{2}$

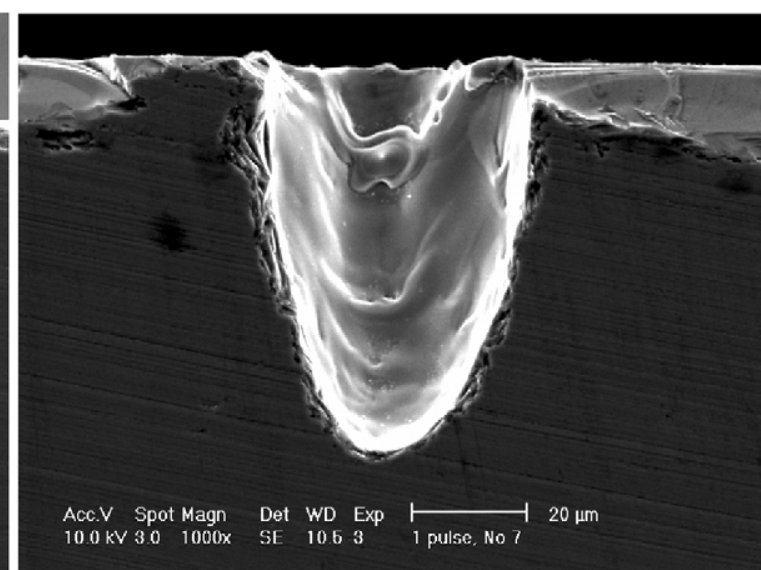

(b) $\mathrm{I}=2 \times 10^{8} \mathrm{~W} / \mathrm{cm}^{2}$

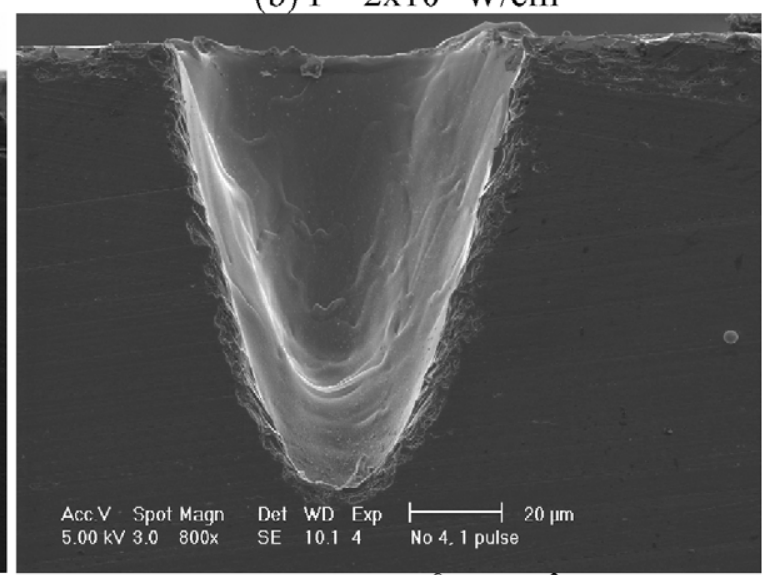

(d) $\mathrm{I}=6 \times 10^{8} \mathrm{~W} / \mathrm{cm}^{2}$

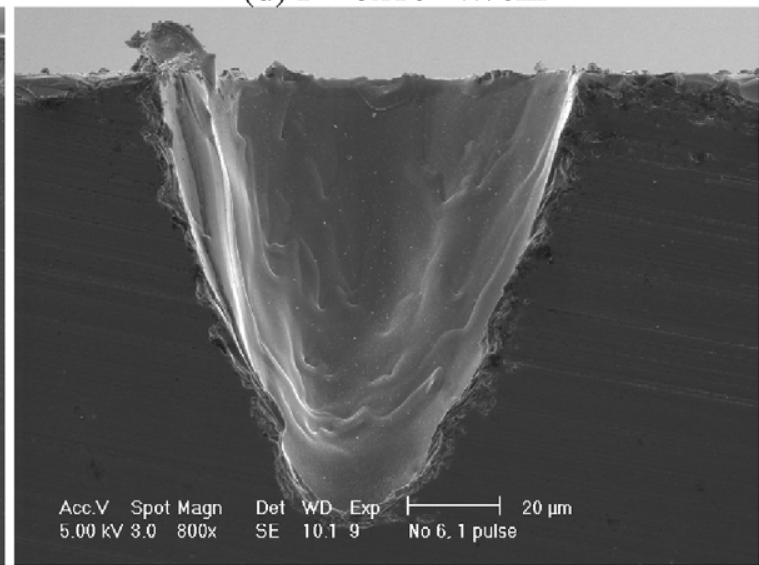

(f) $\mathrm{I}=10^{9} \mathrm{~W} / \mathrm{cm}^{2}$

Figure 6. SEM images of drilled-hole cross-sections.

occur between the pulses due to rapid cooling, depending on the process parameters. In this case, the $\mathrm{L} / \mathrm{V}$ and $\mathrm{S} / \mathrm{L}$ interfaces merge together and become a new solid-vapour (S/V) interface once the solidification process is completed. In this study, if the liquid layer thickness is less than a very small value, the $\mathrm{S} / \mathrm{L}$ interface is replaced by a fictitious interface and the solidification is considered completed. Thus, the temperature field can be further updated using the same mass and energy balance equations with the assumed velocity and temperature profiles even after the $\mathrm{L} / \mathrm{V}$ and $\mathrm{S} / \mathrm{L}$ interface are lost.

\section{Results and discussion}

Figures $6(a)-(f)$ are the SEM images of the cross-sections of the drilled holes. These cross-sections are made using a dicing saw and due to the brittleness of silicon some edges have been broken. From figures $6(a)$ and $(b)$, it can be seen that the melt flow is indeed the dominant mass removal mechanism, shown by the heavy melt ejection and smooth surface morphology. In particular, figure 6(a) clearly shows that the ejected melt is piled at the top surface of the silicon substrate. Considering that the melt flow is the dominant mechanism at low laser intensities 


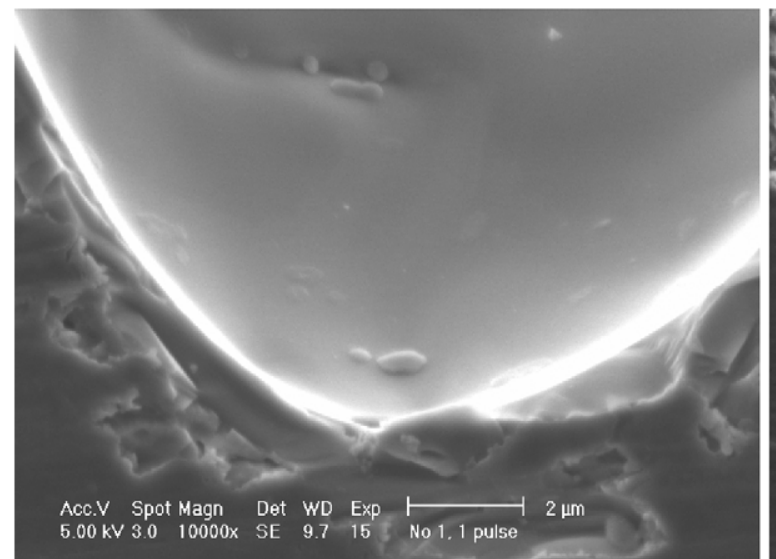

(a) $\mathrm{I}=1 \times 10^{8} \mathrm{~W} / \mathrm{cm}^{2}$

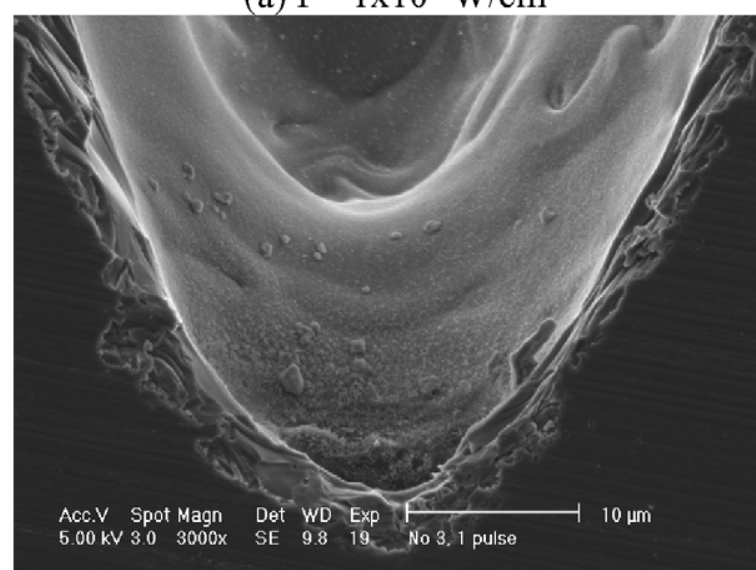

(c) $\mathrm{I}=4 \times 10^{8} \mathrm{~W} / \mathrm{cm}^{2}$

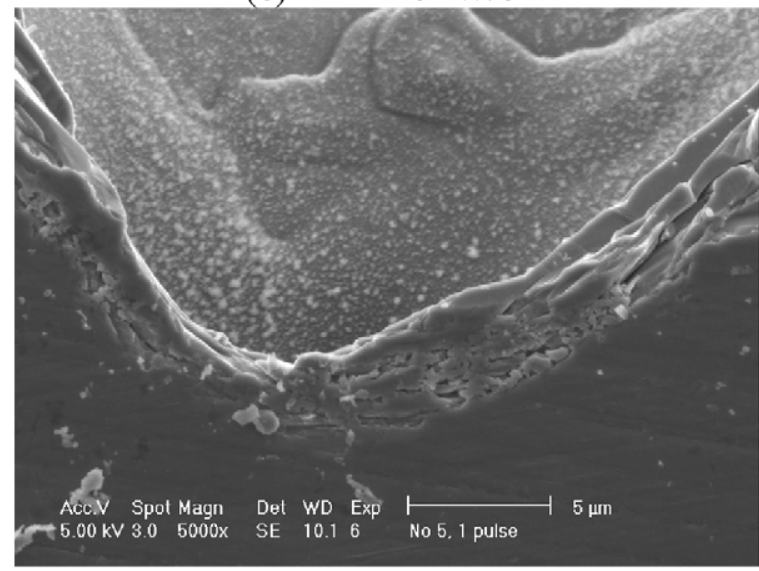

(e) $\mathrm{I}=8 \times 10^{8} \mathrm{~W} / \mathrm{cm}^{2}$

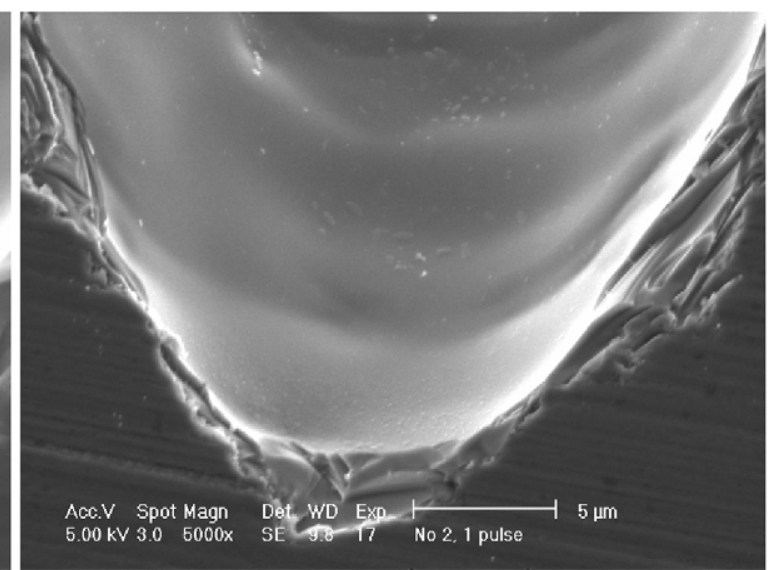

(b) $\mathrm{I}=2 \times 10^{8} \mathrm{~W} / \mathrm{cm}^{2}$

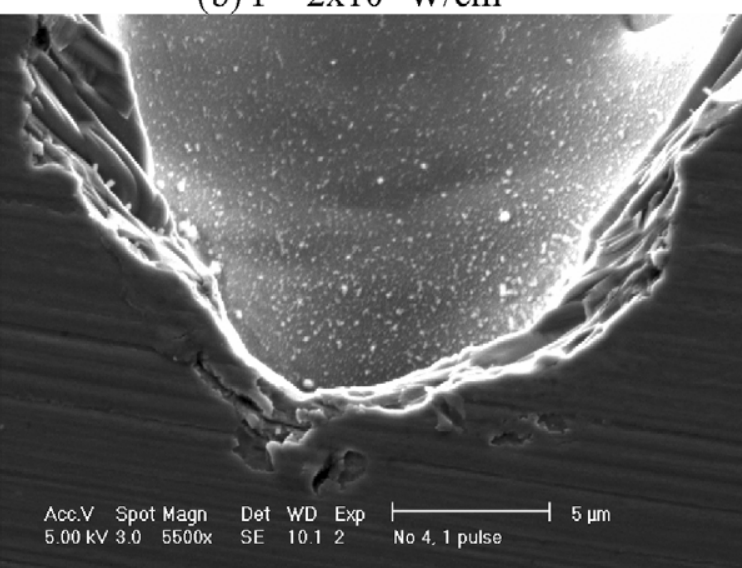

(d) $\mathrm{I}=6 \times 10^{8} \mathrm{~W} / \mathrm{cm}^{2}$

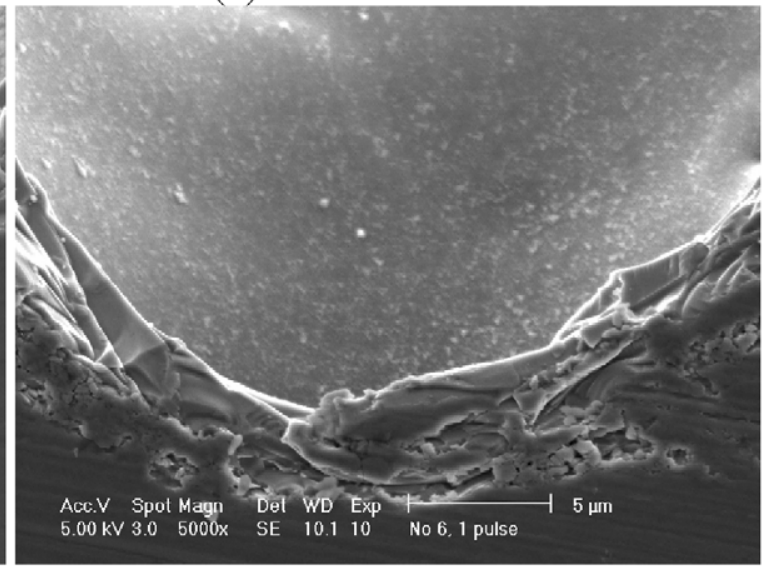

(f) $\mathrm{I}=1 \times 10^{9} \mathrm{~W} / \mathrm{cm}^{2}$

Figure 7. SEM images of drilled-hole cross-sections near the bottom area.

[1], we postulate that evaporation and homogeneous boiling are not dominant mass removal modes at these intensities. On the other hand, it can be seen from figures $6(a)-(f)$ that there is a gradual reduction in the amount of melt ejection. But, even in figure $6(f)$ it is apparent that there was a melt flow during the process. As the intensity increases, more silicon debris is observed on the cavity surface, especially near the bottom, but the average debris size decreases as the intensity goes up (see figure 7). Even though the type of surface morphology that Craciun and co-workers $[17,18]$ had reported for their pulsed laser ablation of single crystalline germanium and silicon samples was not observed, it is believed that both evaporation and homogeneous boiling contributes to the ablation process and debris formation at these laser intensity levels. Considering the size of the debris, it is believed that they are formed mainly from the sub-surface homogeneous nucleation rather than surface evaporation. In fact, it was reported [19] that the ejection of droplets was detected during laser ablation of silicon at $1.06 \mu \mathrm{m}$ for an irradiance as low as $1.1 \times 10^{-8} \mathrm{~W} \mathrm{~cm}^{-2}$, which is close to the lowest intensity 
level used in this experiment. This fact is also proved by the simulation results below.

During a pulsed laser interaction process, solidification due to rapid cooling may occur in between the laser pulses

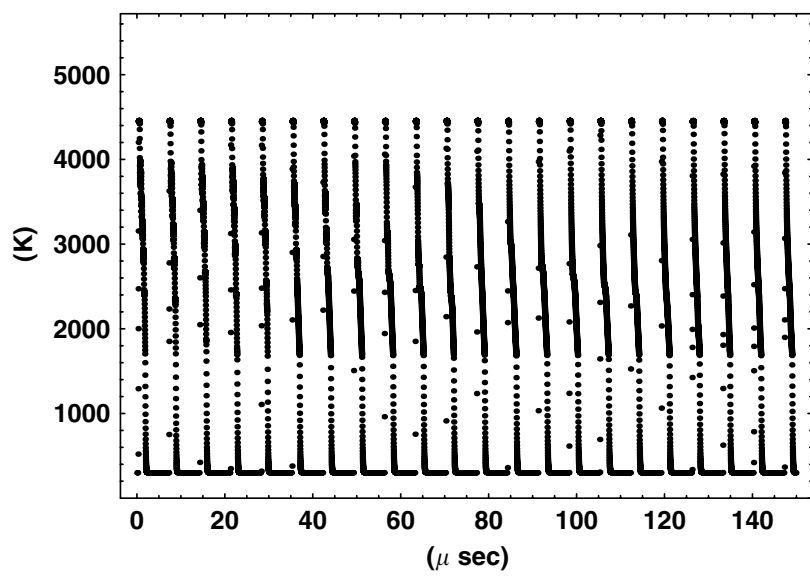

Figure 8. Maximum surface temperature versus time (intensity $=10^{9} \mathrm{~W} \mathrm{~cm}^{-2}$ ).

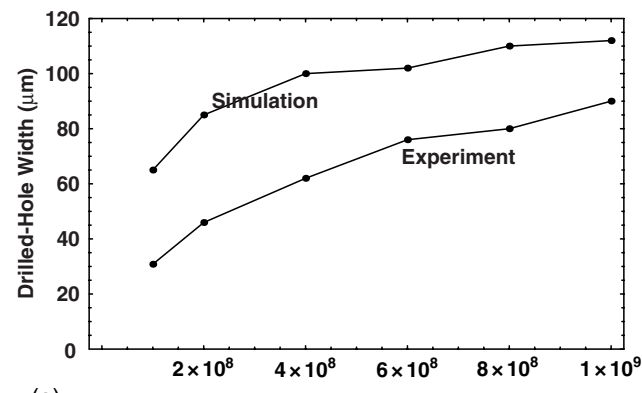

(a)

Peak Intensity $\left(\mathrm{W} / \mathrm{cm}^{2}\right)$
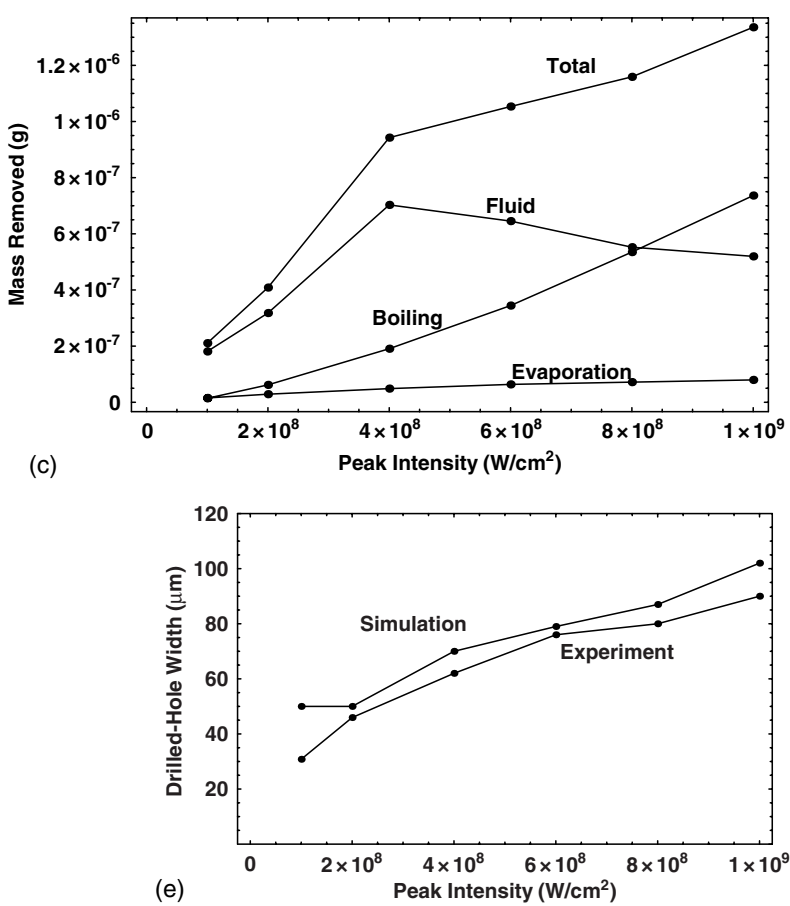

(in this case, these are spikes because only one pulse is used and a pulse consists of 21-22 small spikes due to Q-switching). Figure 8 shows how the surface temperature changes with time during the pulsed laser removal process. The temperature history follows closely the temporal pulse shape. At the given laser intensity, each short spike raises the surface temperature well above $4500 \mathrm{~K}$, and the temperature drops back to almost room temperature during the spike off period. Indeed this figure confirms that homogeneous boiling is very likely to occur since $4500 \mathrm{~K}$ is almost $90 \%$ of the critical temperature of silicon $(5159 \mathrm{~K})$ [10]. It is clear from the figure that silicon is undergoing a process of melting and solidification repeatedly until the laser source is removed.

Figures $9(a)$ and $(b)$ present the results for the simulated hole width/depth and the experimental hole width/depth versus peak intensity. The model over-predicts the width and mostly under-predicts the depth. One encouraging fact, however, is that in both cases the slopes predicted by simulation are in very good agreement with experimental results, which the authors believe is important to study the role of the individual mass loss mode. It is possible that error sources (such as inaccurate measurement of beam shape, fluctuations
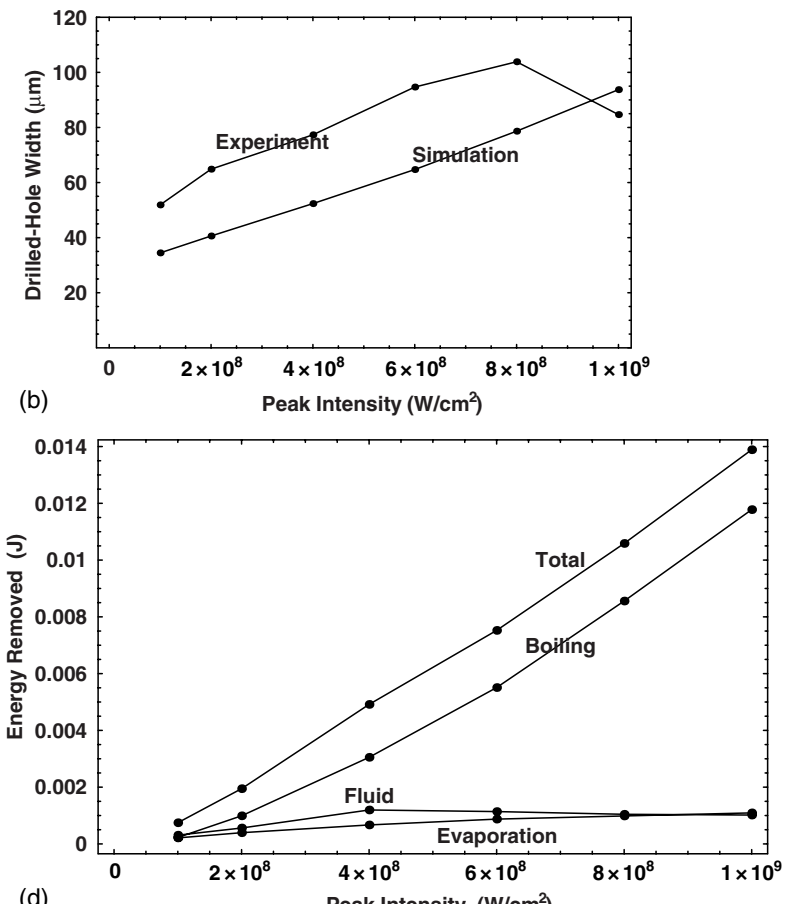

(d)

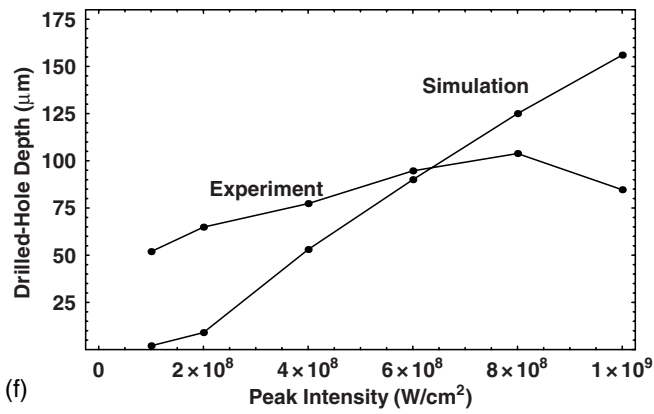

Figure 9. $(a)$ and $(b)$ Measured hole width and depth versus computed hole width and depth, $(c)$ and $(d)$ Simulation results of mass and energy removed (total, due to fluid flow, evaporation and homogeneous boiling) versus peak intensity, $(e)$ and $(f)$ measured hole width and depth versus computed hole width and depth. Melt flow is not simulated intentionally to study the effect of melt flow. 
Table 2. Material properties for silicon (from [20-23]).

\begin{tabular}{ll}
\hline Property, symbol (unit) & Value \\
\hline Melting temperature, $T_{\mathrm{m}}(\mathrm{K})$ & 1683 \\
Normal boiling temperature, $T_{b}(\mathrm{~K})$ & 3514 \\
Critical point temperature, $T_{\mathrm{cr}}(\mathrm{K})$ & 5159 \\
Liquid density, $\rho_{\mathrm{l}}\left(\mathrm{kg} \mathrm{m}^{-3}\right)$ & 2520 \\
Solid density, $\rho_{\mathrm{s}}\left(\mathrm{kg} \mathrm{m}^{-3}\right)$ & 2320 \\
Surface tension, $\sigma$ & $(1) 0.7835-0.65 \times 10^{-3}\left(T-T_{\mathrm{m}}\right)$ for $T<1773 \mathrm{~K}$ \\
& $(2)-1.94789 \times 10^{-11}(T-5108.13)^{3}+0.00238748$ \\
& for $T \geqslant 1773 \mathrm{~K}$ and $T<0.9 T_{\mathrm{cr}}$ \\
& $(3) 3.70923 \times 10^{-7}\left(T_{\mathrm{cr}}-T\right)^{1.5}$ \\
Latent heat of vaporization, $L_{\mathrm{v}}\left(\mathrm{J} \mathrm{kg}^{-1}\right)$ & for $T \geqslant 0.9 T_{\mathrm{cr}}$ \\
Latent heat of fusion, $L_{\mathrm{m}}\left(\mathrm{J} \mathrm{kg}^{-1}\right)$ & $1.3722 \times 10^{7}$ \\
Solid thermal conductivity, $k_{s}\left(\mathrm{~J} \mathrm{~cm}^{-1} \mathrm{~s} \mathrm{~K}\right)$ & $1.797 \times 10^{6}$ \\
& $1521 T^{-1.226}$ for $T \leqslant 1200 \mathrm{~K}$ \\
Liquid thermal conductivity, $k_{l}\left(\mathrm{~J} \mathrm{~cm}^{-1} \mathrm{~s} \mathrm{~K}\right)$ & $8.98 T^{-0.502}$ for $1200 \mathrm{~K}<T<T_{\mathrm{m}}$ \\
Solid constant-pressure specific heat, $C_{\mathrm{ps}}\left(\mathrm{J} \mathrm{g}^{-1} \mathrm{~K}\right)$ & $0.5+2.9 \times 10^{-4}\left(T-T_{\mathrm{m}}\right)$ \\
Liquid constant-pressure specific heat, $C_{\mathrm{pl}}\left(\mathrm{J} \mathrm{g} \mathrm{g}^{-1} \mathrm{~K}\right)$ & 0.694 exp $\left(2.375 \times 10^{-4} T\right)$ \\
Laser beam absorptivity for flat surface & 1050
\end{tabular}

in laser power, and inaccurate material properties) caused these discrepancies. Furthermore, it is believed that the fluid flow model is not very optimized for pulsed laser drilling simulations. In this model, the fluid flow is assumed to be one-dimensional and a simple integration method by assuming a quadratic velocity profile is used to derive an equation to update the melt velocity. If the laser beam is $\mathrm{CW}$, the melt ejection occurs continuously throughout the drilling process, and this one-dimensional model is believed to work well [1]. However, as seen from the surface morphology (See figure 6), the pulsed laser beam now generates complicated situations such as multi-dimensional and complex flow patterns near the melting temperature. It is believed that the model over-predicts the melt flow to some extent because the melt flow enhances radial-direction heat transfer and subsequently leads to wider holes. It is interesting to note in figure $9(b)$ that when the laser peak intensity is $10^{9} \mathrm{~W} \mathrm{~cm}^{-2}$, the hole depth suddenly decreases. Unfortunately, this phenomenon is not captured by the simulation and will not be discussed in this paper.

Figure $9(c)$ shows the mass removed by a single pulse (the total, due to fluid flow, evaporation and homogeneous boiling) versus the peak intensity, while figure $9(d)$ presents the corresponding energy removed by a single pulse (the total, due to fluid flow, evaporation and homogeneous boiling) versus the peak intensity. From these two figures, one can see that as the laser intensity increases, the dominant mass removal mode shifts from fluid flow to homogeneous boiling. Also from figure $9(d)$, it can be seen that the major part of the laser energy is used by homogeneous boiling at higher intensities. In order to study the efficiency of each mass removal mode, the ratio of energy removed by the three modes is computed and listed in table 3. It is shown clearly that irrespective of the laser intensity (between $10^{8}-10^{9} \mathrm{~W} \mathrm{~cm}^{-2}$ ), the ratio of energies needed to remove the same mass by melt flow, evaporation and homogeneous boiling is roughly $1: 8: 9$. Therefore, the melt flow is roughly nine times more efficient than homogeneous boiling, and evaporation and homogeneous boiling are almost equally inefficient. Therefore, it is definitely not an exaggeration to say that fluid flow is the most efficient mass removal process. With a relatively small amount of
Table 3. Mass loss ratios, energy loss ratios and energy needed to remove unit mass (due to melt flow, evaporation and homogeneous boiling) for peak intensities $1,2,4,6,8$ and $10 \times 10^{8} \mathrm{~W} \mathrm{~cm}^{-2}$.

\begin{tabular}{llll}
\hline $\begin{array}{l}\text { Intensity } \\
\left(10^{8} \mathrm{~W} \mathrm{~cm}^{-2}\right)\end{array}$ & $\begin{array}{l}\text { Mass loss } \\
\text { ratios }\end{array}$ & $\begin{array}{l}\text { Energy loss } \\
\text { ratios }\end{array}$ & $\begin{array}{l}\text { Energy needed to } \\
\text { remove unit mass }\end{array}$ \\
\hline 1 & $1: 0.09: 0.08$ & $1: 0.69: 0.73$ & $1: 8.06: 9.40$ \\
2 & $1: 0.09: 0.19$ & $1: 0.71: 1.77$ & $1: 7.78: 9.07$ \\
4 & $1: 0.07: 0.27$ & $1: 0.56: 2.55$ & $1: 8.07: 9.40$ \\
6 & $1: 0.10: 0.53$ & $1: 0.77: 4.83$ & $1: 7.77: 9.06$ \\
8 & $1: 0.13: 0.97$ & $1: 0.94: 8.20$ & $1: 7.26: 8.46$ \\
10 & $1: 0.15: 1.42$ & $1: 1.08: 11.58$ & $1: 7.01: 8.18$ \\
\hline
\end{tabular}

energy, it can remove a substantial amount of material when compared with evaporation and homogeneous boiling.

One more thing to note from figures $9(c)$ and $(d)$ is that homogeneous boiling starts to occur at around $1 \times 10^{8} \mathrm{~W} \mathrm{~cm}^{-2}$, which is the lowest laser intensity used in this study. The experimental results (figures 6 and 7) prove this, and as mentioned earlier, a similar result was reported in the literature [19].

An interesting observation from figures $9(c)$ and $(d)$ is that at such high intensities, evaporation contributes very little to the mass and energy removal process of silicon. This may be due to the short pulse width of the laser and the boiling and critical point. The boiling point of silicon is $3538 \mathrm{~K}$ while the critical point is $5159 \mathrm{~K}$. The difference between the two is only $1621 \mathrm{~K}$, which is very small compared with that of steel. In the case of steel, the difference is $6117 \mathrm{~K}$ (normal boiling temperature: $3133 \mathrm{~K}$, critical temperature: $9250 \mathrm{~K}$ ) [1]. Considering that evaporation increases exponentially as a function of temperature [13], it is believed that the farther the critical point is from the boiling point, the more evaporation we can expect near the critical point of the material. Therefore, evaporation plays a relatively small role in the ablation of silicon, which justifies the evaporation curves in figures $9(c)$ and $(d)$. In fact, this in turn justifies the very high chances of having homogeneous boiling in the laser ablation of silicon. As seen from figures 6 and 7, there is evidence that progressively less melt flow contributes to the total mass removal mechanism as the intensity goes up, which justifies the existence of homogeneous boiling. In summary, 

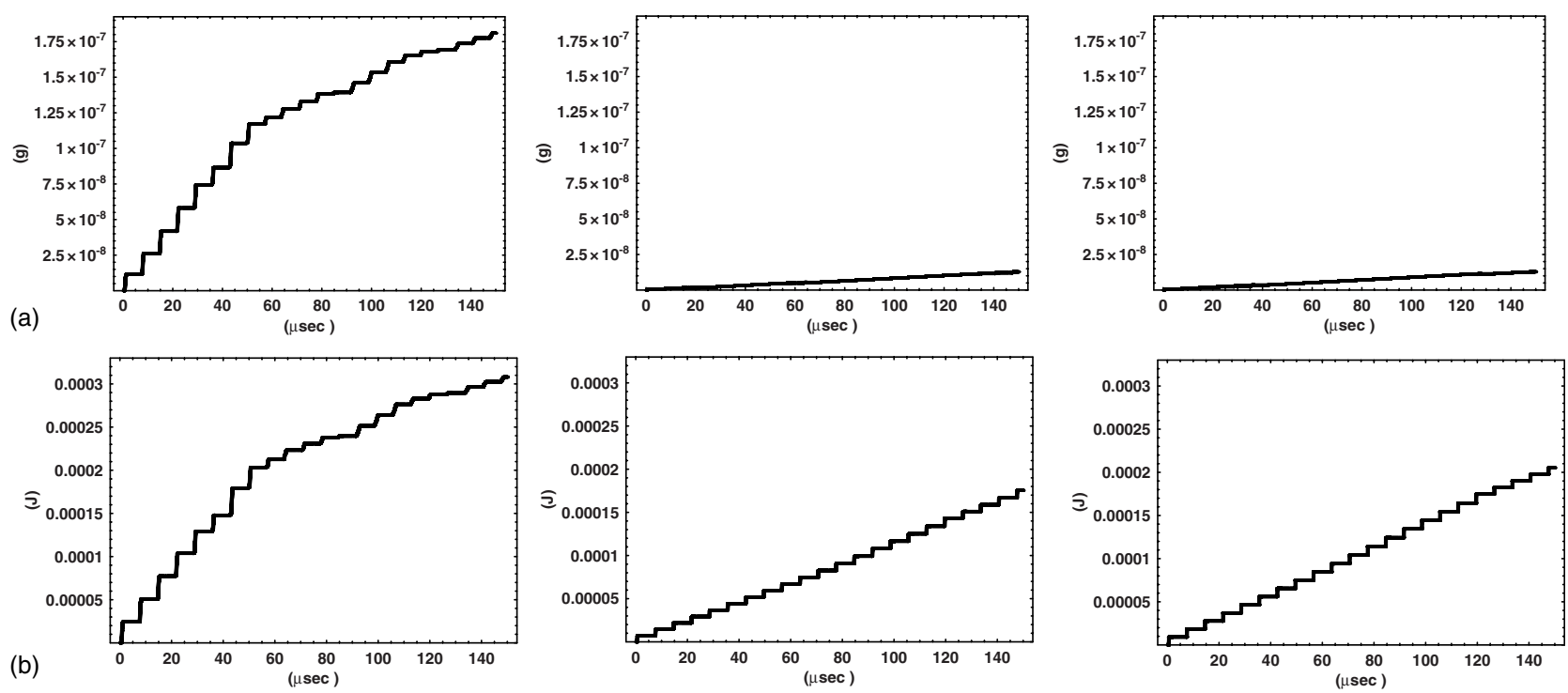

Figure 10. For $I=10^{8} \mathrm{~W} \mathrm{~cm}^{-2}(a)$ accumulated mass loss versus time, $(b)$ accumulated energy loss versus time (left to right: melt flow, evaporation, homogeneous boiling).

the mass removal mechanism shifts quickly from melt flow to homogeneous boiling, with not much contribution from evaporation as was thought to be.

In order to investigate the effect of the one-dimensional fluid flow algorithm, the same simulations were intentionally performed without the thermo-capillary effect and recoil pressure. Therefore, in this case, there is no melt flow. figures $9(e)$ and $(f)$ show the results for the simulated hole width/depth and the experimental hole width/depth versus peak intensity without simulating melt flow. This time, the model still overestimates the hole width but the results are much better than in the case which involves melt flow. The overall trend of the two curves agree with each other by as little as $\sim 5.3 \%$ to as much as $\sim 13.3 \%$ for the majority of data points. On the other hand, the simulation fails completely in predicting the hole depth, and the slopes of the two curves do not have a common trend. Hence, it is apparent that the fluid flow algorithm exaggerates the energy transfer in the radial direction and, therefore, over-predicts hole depths. This demonstrates the importance of the fluid flow model in the pulsed laser drilling simulation even at the intensity levels of $10^{8}-10^{9} \mathrm{~W} \mathrm{~cm}^{-2}$. It is believed that the current one-dimensional model with a quadratic velocity file is probably the major cause of errors.

Figure 10(a) shows the time history of the accumulated mass losses due to melt flow, evaporation and homogeneous boiling for the peak intensity of $10^{8} \mathrm{~W} \mathrm{~cm}^{-2}$. As seen clearly, the mass removal processes by melt flow, evaporation and homogeneous boiling are all discontinuous, and, therefore, the accumulated mass losses for melt flow, evaporation and homogeneous boiling increase in a step-like pattern. At the given laser intensity, the melt flow is the dominant mass removal mechanism, while the effects of evaporation and homogeneous boiling are negligible. The mass loss ratios by melt flow, evaporation and homogeneous boiling are 1:0.09:0.08, respectively (see table 3). Melt flow is indeed the dominant mode while both evaporation and homogeneous boiling exist but their contributions are very small.
Figure $10(b)$ shows the time history of the accumulated energy losses due to melt flow, evaporation and homogeneous boiling. First of all, it can be seen that the pattern is very similar to that of accumulated mass loss. The energy loss ratio by melt flow, evaporation and homogeneous boiling is $1: 0.69: 0.73$, and the ratio of energies needed to remove unit mass is $1: 8.06: 9.40$. Hence, mass removal by melt flow is the most efficient mechanism, which coincidently is also the dominant mass removal mechanism for the given laser intensity. Similar trends are observed for peak intensities 2, 4, 6 and $8 \times 10^{8} \mathrm{~W} \mathrm{~cm}^{-2}$ (see table 3 ).

Figure 11(a) shows the time history of the accumulated mass losses due to melt flow, evaporation and homogeneous boiling for the peak intensity of $10^{9} \mathrm{~W} \mathrm{~cm}^{-2}$. As in the case of $10^{8} \mathrm{~W} \mathrm{~cm}^{-2}$, the mass removal processes by melt flow, evaporation and homogeneous boiling are all discontinuous and the accumulated mass losses for melt flow, evaporation and homogeneous boiling increase in a step-like pattern. The major difference between $10^{9} \mathrm{~W} \mathrm{~cm}^{-2}$ and $10^{8} \mathrm{~W} \mathrm{~cm}^{-2}$ is that homogeneous boiling is now the dominant mass removal mechanism while the effect of evaporation remains negligible. However, melt flow still plays a significant role in the mass removal process even though homogeneous boiling is the dominant mechanism. The ratio of mass removed by melt flow, evaporation and homogeneous boiling is $1: 0.15: 1.42$ (see table 3).

Figure $11(b)$ shows the time history of the accumulated energy losses due to melt flow, evaporation and homogeneous boiling. The ratio of energies removed by melt flow, evaporation and homogeneous boiling is $1: 1.08: 11.58$. Therefore, the energies needed to remove unit mass are $1: 7.01: 8.18$, respectively. Similarly, mass removal by melt flow is the most efficient mechanism, while mass removal by homogeneous boiling is the least efficient. This brings up a very interesting observation. As seen from these simulation and experimental results, the higher the intensity, the less beneficial it may be in terms of energy efficiency. This is because, as intensity increases, the dominant mass removal 

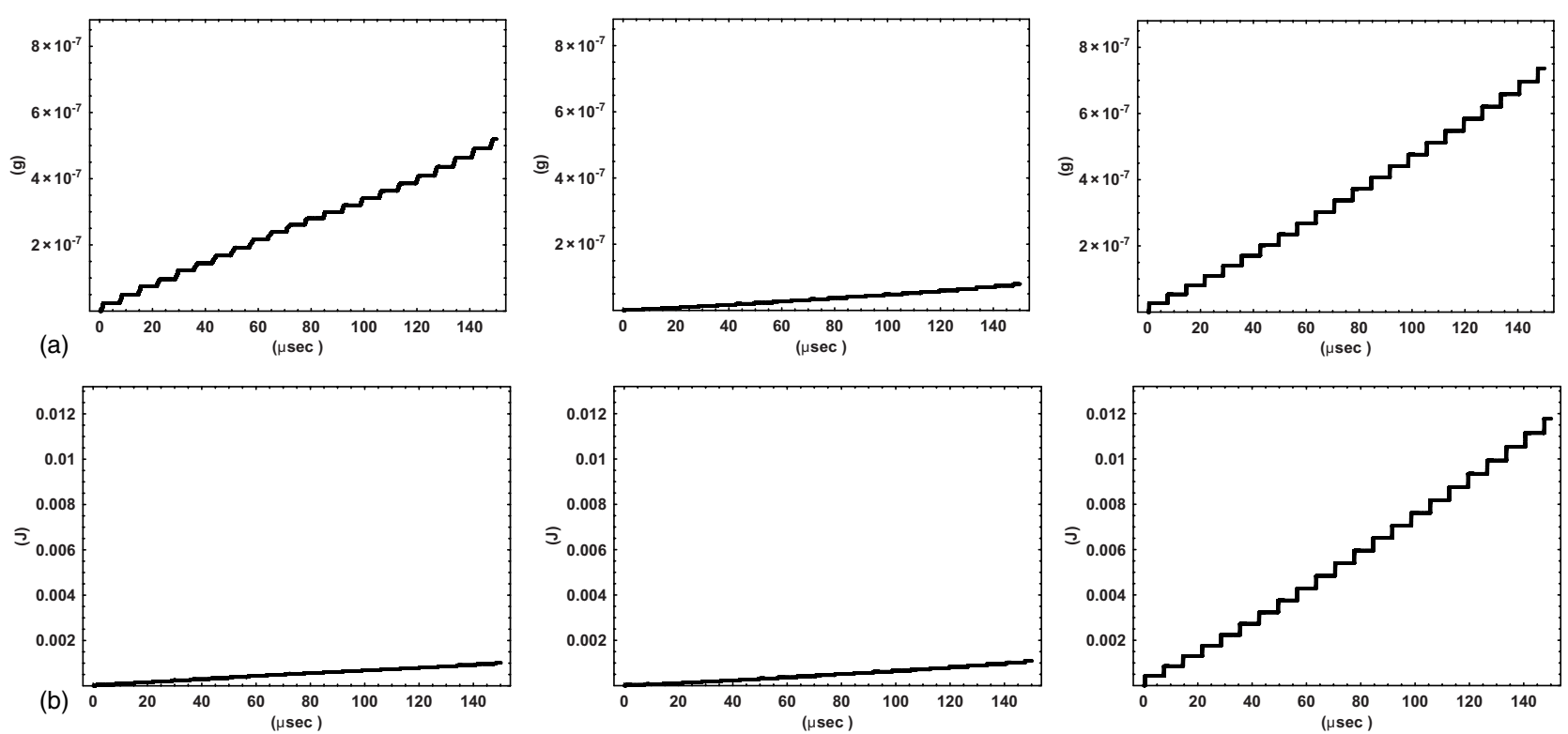

Figure 11. For $I=10^{9} \mathrm{~W} \mathrm{~cm}^{-2}(a)$ accumulated mass loss versus time, $(b)$ accumulated energy loss versus time for intensity (left to right: melt flow, evaporation, homogeneous boiling).

mechanism shifts from the melt flow to homogeneous boiling as seen from this study.

\section{Conclusion}

A study of single pulse Q-switched DPSSL interaction with silicon was conducted numerically and experimentally. Both simulation results and experimental observations show that as the intensity increases from $10^{8}$ to $10^{9} \mathrm{~W} \mathrm{~cm}^{-2}$, the dominant mass removal mode changes from melt ejection to homogeneous boiling. Simulation results show that evaporation does not contribute much to the total mass removal process for all the intensities considered in this study. In addition, homogeneous boiling seems to start at around $1 \times 10^{8} \mathrm{~W} \mathrm{~cm}^{-2}$ as described in [19]. It is interesting that melt ejection mode is about 7-9 times more efficient than evaporation and homogeneous boiling modes in terms of energy efficiency.

\section{Acknowledgment}

This work was supported in part by the Singapore Institute of Manufacturing Technology.

\section{References}

[1] Ki H, Mohanty P S and Mazumder J 2001 Modelling of high-density laser-material interaction using fast level set method J. Phys. D: Appl. Phys. 34 364-72

[2] Schmidt M and Eber G 2003 The future of lasers in electronics Int. Cong. on Applications of Lasers and Electro-Optics (ICALEO) (Jacksonville, Florida, USA: Laser Institute of America)

[3] Pronko P P et al 1995 Thermophysical effects in laser processing of materials with picosecond and femtosecond pulses J. Appl. Phys. 78 6233-40
[4] Jandeleit J et al 1998 Fundamental investigations of micromachining by nano- and picosecond laser radiation Appl. Surf. Sci. 129 885-91

[5] Shirk M D and Molian P A 1998 A review of ultrashort pulsed laser ablation of materials J. Laser Appl. 10 18-28

[6] Gross T S, Hening S D and Watt D W 1991 Crack formation during laser cutting of silicon J. Appl. Phys. 69 983-9

[7] Sokolowski-Tinten K, Bialkowski J and Vonderlinde D 1995 Ultrafast laser-induced order-disorder transitions in semiconductors Phys. Rev. B 51 14186-98

[8] Simon P and Ihlemann J 1996 Machining of submicron structures on metals and semiconductors by ultrashort UV-laser pulses Appl. Phys. A-Mater. Sci. Process. 63 505-8

[9] Walker L A, Maynard R L and Clark W 2002 Atmospheric affects on ultrashort-pulsed material processing 21st Int. Congr. on Applications of Lasers and Electro-optics (ICALEO) (Scottsdale, AZ)

[10] Miotello A and Kelly R 1995 Critical-assessment of thermal models for laser sputtering at high fluences Appl. Phys. Lett. 67 3535-7

[11] Fabbro R and Chouf K 2000 Keyhole modelling during laser welding J. Appl. Phys. 87 4075-83

[12] Sethian J A 1999 Level Set Methods and Fast Marching Methods 2nd edn (Cambridge: Cambridge University Press)

[13] Knight C J 1979 Theoretical modelling of rapid surface vaporization with back pressure AIAA J. 17 519-23

[14] Ytrehus T and Ostmo S 1996 Kinetic theory approach to interphase processes Int. J. Multiph. Flow 22 133-55

[15] Carey V P 1992 Liquid-Vapour Phase Change Phenomena (Bristol, PA: Hemisphere)

[16] Machan J et al 1996 Diode-pumped Nd : YAG laser for precision laser machining J. Laser Appl. 8 225-32

[17] Craciun V et al 1998 Subsurface boiling during pulsed laser ablation of Ge Phys. Rev. B 58 6787-90

[18] Craciun V et al 2002 Laser-induced explosive boiling during nanosecond laser ablation of silicon Appl. Surf. Sci. 186 288-92

[19] Craciun V 2001 Comment on Evidence for phase-explosion and generation of large particles during high power nanosecond laser ablation of silicon Appl. Phys. Lett. 79 442-3 
[20] Przyborowski M et al 1995 Surface-tension measurement of molten silicon by the oscillating drop method using electromagnetic-levitation J. Cryst. Growth 151 60-5

[21] Ivlev G D and Gatskevich E I 1999 Solidification temperature of silicon surface layer melted by pulsed laser irradiation Appl. Surf. Sci. 143 265-71

[22] Rhim W K and Ohsaka K 2000 Thermophysical properties measurement of molten silicon by high-temperature electrostatic levitator: density, volume expansion, specific heat capacity, emissivity, surface tension and viscosity J. Cryst. Growth 208 313-21

[23] Yoo J H et al 2000 Explosive change in crater properties during high power nanosecond laser ablation of silicon J. Appl. Phys. 88 1638-49

[24] Ki H 2001 Modelling and measurement of processes with liquid-vapor interface created by high power density lasers Mechanical Engineering Department (Ann Arbor, MI: University of Michigan) 